Firdous Habib and Madhu Bajpai

\title{
UV CURABLE HEAT RESISTANT EPOXY ACRYLATE COATINGS
}

\author{
Department of Oil \& Paint Technology, Harcourt Butler Technological Institute (HBTI) \\ Kanpur-208002 (UP), India; firdaus24@gmail.com
}

Received: December 11, 2009 / Accepted: April 16, 2010

(C) Firdous H., Bajpai M., 2010

\begin{abstract}
Polymeric materials are exposed to high temperatures that results in lowering of the film integrity. A blend of an epoxy resin with the silicone acrylate resin was developed to provide high heat resistance UV cured coatings. Earlier siliconized epoxy coatings had been developed by conventional curing. But due to environmental awareness, high productivity rate, low process costs and energy saving UV curable coatings are enjoying considerable growth. Thermally stable UV cured coatings used in the present study were developed from silicone acrylate and epoxy acrylate resin with different diluents and photoinitiator. Such coatings provide higher thermal stability $(693 \mathrm{~K})$ along with physical and chemical resistance. In addition, such coatings can also be obtained by using functional amino silanes. The resin developed provides a simple and practical solution to improve heat resistance along with physical and chemical resistance of the UV cured coatings. The purpose of this research paper is to develop UV curable heat resistant coatings by the combination of inorganic and organic polymer, taking epoxy acrylate as a base resin.
\end{abstract}

Keywords: heat resistance, silicone acrylate, UV-curing.

\section{Introduction}

Epoxy resins are commercially used in coatings and various structural applications. Through the proper selection of resin modifier and curing agent, the cured epoxy resin can be tailored to specific performance characteristics. The choice depends upon the cost, processing and performance requirement. They may be used for coating without modification or they may be esterified with acrylic acid or methacrylic acid [1,2]. Epoxy resins are characterized by low shrinkage, ease of cure and processing, excellent moisture, solvent and chemical resistance, and good adhesive strength. However their shortcomings are low fracture energy, low thermal stability, low pigment holding ability, poor hydrophobicity, weathering and impact strength which restrict their wide application in the field of coatings and paints. To improve these properties a second component such as rubber, amino terminated butadiene nitrile rubber, polyurethane, silicone and some other thermoplastics are added as modifiers for epoxy resin. Silicone is considered to be one of the suitable modifiers for epoxy resin, owing to its superior thermal and thermooxidative stability, excellent moisture resistance, partial ionic nature, low surface energy, good flame retardancy and free rotations of chains about Si-O bonds, good hydrophobicity, compressivity and doping action [3-5].

Structural materials have limitations for use at high temperature due to oxidation chemical reaction and corrosion; therefore, to provide improved reliability at high operating temperature, high heat and corrosion-resistant protective coatings are used. Epoxy silicone based coatings have high thermal stability, excellent adhesion, good flexibility, and improved acid and solvent resistance compared to conventional epoxy coatings. In the past heat resistant siliconized epoxy coating had been developed by conventional curing. Conventional organic protective coatings fail due to carbonization and evolution of aggressive gases. Such films age rapidly at elevated temperature (> $373 \mathrm{~K}$ ) and exhibit loss of flexibility, elasticity, adhesion, and protective value. In general, physical properties of highly desirable heat resistant coatings have a high glass transition temperature (> 523 K) and a high decomposition temperature $(673 \mathrm{~K})$ [6]. Recently heat resistant UV-curable coatings have enjoyed considerable growth due to environmental awareness and increased productivity compared to traditional method of curing [7, 8]. UV curing process has attractive advantages over thermal curing. Their major advantages are high-speed process, low energy consumption due to the operation at room temperature, and environmental friendliness by avoiding solvent exposure. In contrast the usage of UV curing can cut process costs, decrease pollution and save energy [9-14]. Novolac acrylate provides a higher aromatic content and more crosslink sites in the pendent positions along the backbone of molecules than conventional epoxies [15]. Further its blending with silicone acrylate enhances the 
thermal stability thus giving high heat resistance coating. The utility of silicon-based coatings has evolved from specialty high performance applications into broad usage throughout the coatings industry.

In the present study a thermally stable UV curable epoxy coating has been developed by the combination of silicone based inorganic and organic polymer. It has been observed that use of silicone invariably enhances the thermal stability and chemical corrosion resistance of the epoxy coating. Besides thermal stability silicone provides better flexibility and gloss to coatings.

\section{Experimental}

\subsection{M aterials}

Epicholorohydrin (ECH), acrylic acid and hydroquinone was obtained from E. Merck. Methylhydrogendimethyl siloxane was purchased from Aldrich. Trimethylolpropane triacrylate (TMPTA), pentaerythritol triacrylate (PETA) were from Aldrich Co. Ltd., while 1,6-hexanediol diacrylate (HDDA) and 2,2diethoxyacetophenon (DEAP) was procured form Flucka.

\subsection{Synthesis of N ovolac/ Cresol Resin}

Novolac resin was prepared by condensation reaction between $\mathrm{phenol} / \mathrm{cresol}$ and formaldehyde in acidic condition. Initially phenol/cresol ( $1 \mathrm{~mol}$ ) with some quantity of water was taken in three neck flask. The $\mathrm{pH}$ was adjusted to 0.5 with sulphuric acid (used as catalyst) and the contents were heated to $363 \mathrm{~K}$ under constant stirring. The required amount $(0.5 \mathrm{~mol})$ of formaldehyde $(37 \%$ formaline solution) was added over a period of $3 \mathrm{~h}$ through a dropping funnel, and stirring was continued for additional 30 minutes, water was then removed under vacuum. The purified resin was analyzed by infrared (IR) spectroscope and nuclear magnetic resonance ( ${ }^{1} \mathrm{H}$ NMR) spectroscope.

\subsection{Synthesis of Epoxy Novolac/ Cresol Resin}

Laboratory prepared epoxy novolac/cresol resin was reacted with epichlorohydrin in 1:10 molar ratio at $383 \mathrm{~K}$ and $40 \%$ sodium hydroxide solution was added gradually to the reactants over a period of $3 \mathrm{~h}$ through a dropping funnel. After completion of the reaction the reaction mixture was subjected to distillation under vacuum for removal of unreacted epichlorohydrin, salt $(\mathrm{NaCl})$ was removed by washing with hot water and then water was removed through vacuum distillation. The resulting viscous product was analyzed by infrared (IR) spectroscope and nuclear magnetic resonance ( ${ }^{1} \mathrm{H}$ NMR) spectroscope.

\subsection{Synthesis of N ovolac/ Cresol Acrylate Resin}

Acrylation of above prepared epoxy resin was carried out by using 1:0.9 molar ratios of epoxide and acrylic acid in presence of triethylamine as catalyst (1 Phr) and hydroquinone (200 ppm) as inhibitor. The extent of reaction was determined by calculating the acid value [16] at definite time intervals. The residual product was washed with water during stirring. Water was removed under reduced pressure and the product was dried and subjected to IR analysis.

\subsection{Synthesis of Silicone Acrylate Resin}

Acrylated silicone resin was prepared by the reaction of methylhydrogendimethyl siloxane with ally methyl acrylate in the presence of $\mathrm{H}_{2} \mathrm{PtCl}_{6}$ (catalyst) at room temperature (Scheme 1). Prepared resin was characterized by IR.

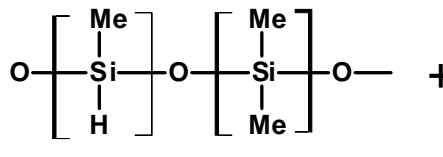

Methylhydrogen dimethyl Siloxane<smiles>C=C(C)OC(=O)C(=C)C</smiles>

allymethyl acrylate
Room temper ature

$\mathrm{H}_{2} \mathrm{PtCl}_{6}$<smiles>C=C(C)C(C)(C)OCC[Si](C)(OC)O[Si](C)(OC)[N+](=O)[O-]</smiles>

Silicone acrylate

Scheme 1 


\subsection{Characteristics of Epoxy Novolac/Cresol Resin}

The epoxide equivalent weight of the prepared epoxy novolac resin (NE) was determined by pyridinium chloride method. Specific gravity was determined by hydrometer while viscosity of the epoxy novolac resin was determined by Brookfield Viscometer (ASTM-1824-66) in methyl ethyl ketone.

\subsection{Characteristics of Acrylated Resin}

The acid value of the prepared epoxy acrylate resin was determined with respect to time until the resin had an acid value of 5 and $6 \mathrm{mg} \mathrm{KOH} / \mathrm{g}$ resin [17]. Viscosity of resin is determined by brookfield viscometer (ASTM-D182466). The color of the resin was determined by gardener color standard using ASTM-D 1544. The refractive index of the prepared epoxy acrylate resins were determined by Abbe Refractometer using ASTM-D 1218 method.

\subsection{Preparation of Test Samples}

The prepared acrylate resins (NA and CA) were mixed with calculated amount of reactive diluents i.e. TMPTA, DETA and HDDA along with silicone acrylate resin and photoinitiators. The films were applied on the mild steel and glass panels with the film applicator of approximate $15 \mu \mathrm{m}$ film, the coated panels were then exposed to UV-lamp of $80 \mathrm{~W} / \mathrm{cm}$ for curing. The panels were evaluated for various film characteristics. Thermogravimetric analysis of the samples were carried out (on TGA V5.1A DuPont 2100 by heating at the rate of $293 \mathrm{~K} / \mathrm{min}$ ) to study the thermal behavior of the coatings (Table 3).

Coding and characterization of epoxy novolac resin

Table 1

\begin{tabular}{|l|c|c|c|c|lc|}
\hline \multicolumn{1}{|c|}{ Resin } & Code & $\begin{array}{c}\text { Sp.gravity at } \\
298 \mathrm{~K}\end{array}$ & $\begin{array}{c}\text { Viscosity } \\
\text { at 298 K }\end{array}$ & $\begin{array}{c}\text { Epoxide } \\
\text { eq. wt. }\end{array}$ & \multicolumn{2}{|c|}{ Solubility } \\
\hline Epoxy Novolac Resin & $\mathrm{NE}$ & 1.148 & 11500 & 185 & $\begin{array}{l}\text { Alcohols, dioxane, ketone, } \\
\text { ester }\end{array}$ \\
\hline Cresol Epoxy Resin & $\mathrm{CE}$ & 1.142 & 10500 & 180 & $\begin{array}{l}\text { Alcohols, dioxane, ketone, } \\
\text { ester }\end{array}$ \\
\hline
\end{tabular}

Table 2

Coding and characterization of epoxy acrylate resin

\begin{tabular}{|l|c|c|c|c|c|}
\hline Resin & Code & $\begin{array}{c}\text { Acid value, } \\
\mathrm{mgKOH} / \mathrm{g}\end{array}$ & $\begin{array}{c}\text { Refractive } \\
\text { index }\end{array}$ & $\begin{array}{c}\text { Viscosity at } \\
333 \mathrm{~K}\end{array}$ & $\begin{array}{c}\text { Color } \\
\text { (Gardner) }\end{array}$ \\
\hline Novolac Acrylate Resin & $\mathrm{NA}$ & 6 & 1.534 & 18000 & $3 \mathrm{G}$ \\
\hline Cresol Acrylate Resin & $\mathrm{CA}$ & 5 & 1.521 & 16000 & $2 \mathrm{G}$ \\
\hline
\end{tabular}

Table 3

Formulation of coatings with silicone compound

\begin{tabular}{|l|l|c|c|c|c|c|c|}
\hline \multirow{2}{*}{ No. } & \multirow{2}{*}{ Ingredients } & \multicolumn{7}{c|}{ Samples, g } \\
\cline { 3 - 8 } & & I & II & III & IV & V & VI \\
\hline 1. & NA & 4 & 4 & 4 & - & - & - \\
\hline 2. & CA & - & - & - & 4 & 4 & 4 \\
\hline 3. & SA & 0.5 & 0.7 & 0.9 & 0.5 & 0.7 & 0.9 \\
\hline 4. & TMPTA & 1.7 & 1.7 & 1.7 & 1.7 & 1.7 & 1.7 \\
\hline 5. & HDDA & 1.7 & 1.7 & 1.7 & 1.7 & 1.7 & 1.7 \\
\hline 6. & PETA & 1.9 & 1.7 & 1.5 & 1.9 & 1,7 & 1.5 \\
\hline 7. & DEAP & 0.2 & 0.2 & 0.2 & 0.2 & 0.2 & 0.2 \\
\hline
\end{tabular}




\section{Results and Discussion}

\subsection{Synthesis of Novolac Resin}

The methylolation of phenol was carried out with formaldehyde in the presence of sulphuric acid. The $\mathrm{pH}$ of the reaction mixture was adjusted to 0.5 . The formylation reaction was carried out with 0.5 mol ratio of phenol-toformaldehyde. Therefore, under these experimental conditions the complete formylation might be expected to yield resin with a high ortho-para linkages for the phenolic novolac resin (Scheme 2). A methylene glycol is protonated by an acid from the reaction medium, which then releases water to form a hydroxymethylene cation (step I). This ion hydroxyalkylates a phenol via electrophilic aromatic substitution. The rate determining step of the sequence occurs in step II where a pair of electrons from the phenol ring attacks the electrophile forming a carbocation intermediate. The methylol group of the hydroxymethylated phenol is unstable in the presence of acid and loses water readily to form a benzylic carbonium ion (step III). This ion then reacts with another phenol to form a methylene bridge in another electrophilic aromatic substitution. This major process repeats until the formaldehyde is exhausted. The completion of the methylolation reaction was checked by periodic withdrawal of reaction mixture to analyze free formaldehyde using hydroxyl amine hydrochloride [18].<smiles>C=CC=[OH+]</smiles>

(Step I)<smiles>OC[C@H]1C=CC=C[C@H]1O</smiles>

(Step II)<smiles>[CH2+]c1ccccc1O</smiles>

(Step III)<smiles>[CH2+]c1ccccc1O</smiles><smiles>Oc1ccccc1</smiles><smiles>[CH]=C</smiles><smiles>Oc1ccccc1Cc1ccccc1O</smiles>

Scheme 2

\subsection{Synthesis of Epoxy Novolac/Cresol Resin}

The novolac based epoxy resin was synthesized by the reaction with epichlorohydrin $(\mathrm{ECH})$. The number of glycidyl groups per molecule in the resin depend upon the number of phenolic hydroxyls in the starting novolac, the extent to which they were reacted and the extent to which the lowest molecular species were polymerized during synthesis. Theoretically, all the phenolic hydroxyls might be reacted, but in practice all of them did not react because of steric hindrance. The reaction between $\mathrm{ECH}$ and novolac resin might be thought to proceed in a similar fashion as in the work given by Lee and Neville [19]. The epoxide group of ECH reacted with phenolic hydroxyls under the alkaline medium and formed chlorohydrin ether, which underwent dehydrochlorination reaction and resulted in glycidyl ether. The structure of the epoxy resin may be proposed as in Scheme 3. 


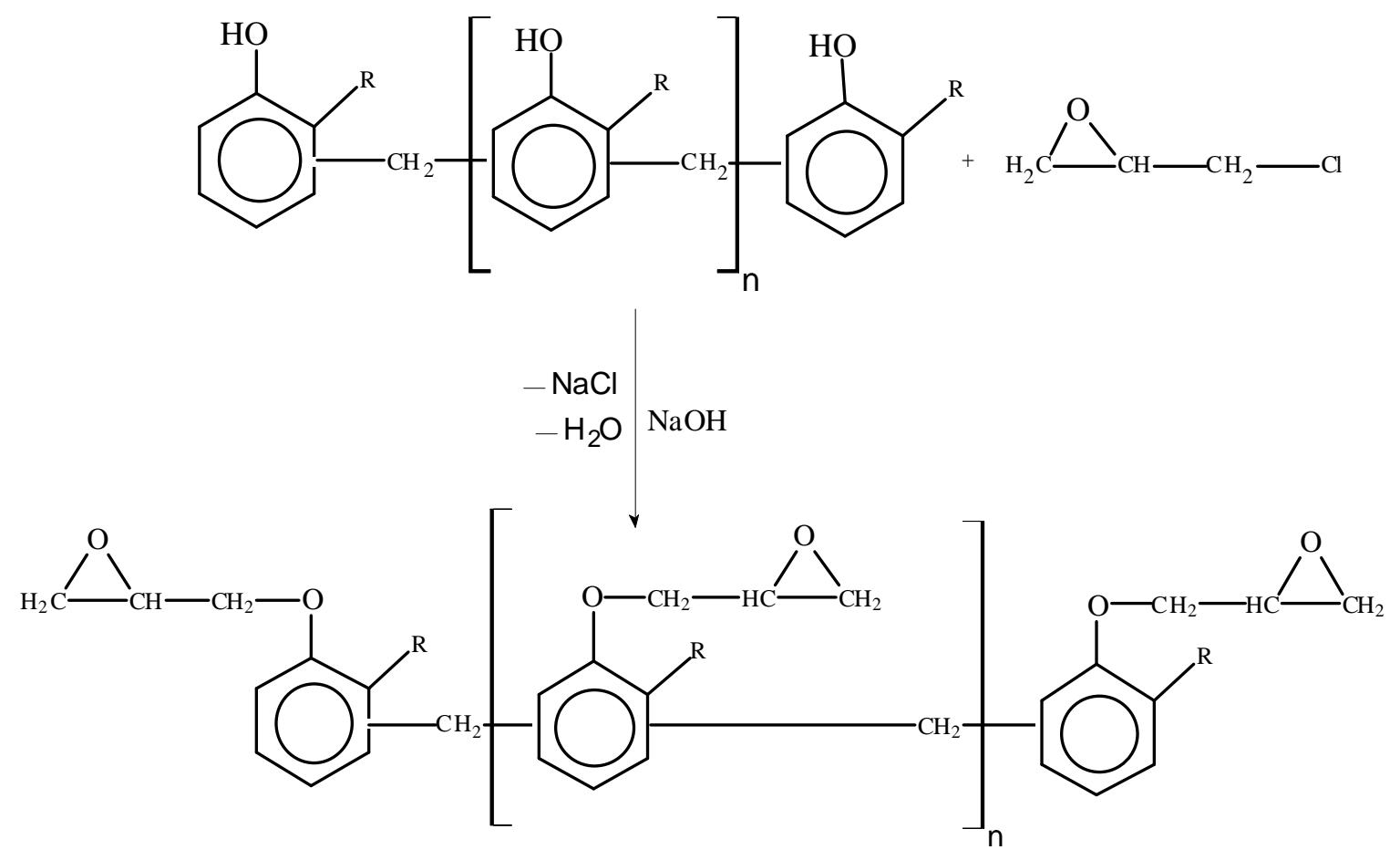

Scheme 3

\subsection{Synthesis of N ovolac/ Cresol Acrylate Resin}

The esterification reaction takes place between epoxidized novolac and acrylic acid in the presence of triethyl amine, epoxy group reacts with the carboxyl ionic group to form addition polymeric hydroxy ester. Epoxide resins react with carboxylic acid to form esters. Reaction takes place between the carboxyl group of the acid and both the epoxy and hydroxyl groups of the epoxides (Scheme 4). In step I the tertiary amine interacts with acrylic acid and abstracts its hydrogen as cation thus producing a corboxylate anion. In step II this carboxylate anion undergoes nucleophilic addition to electron deficient carbon atom of epoxy group and produces an alcoholate anion. In step III alcoholate anion abstracts the proton from amine and completes the reaction with formation of ester and regeneration of amine. The carboxylic anion then attacks on the other unreacted epoxy group till all epoxy and acrylic acid get exhausted, which results in the formation of epoxy acrylate. The degree of esterification is an important parameter that may affect the coating property, and in the present study the reaction was carried out until the acid value reached less than 6 . The change in acid value with reaction time is because of the higher concentration of reactive sites and greater possibility of association of acid and epoxide groups and that the reactivity of functional group is independent of molecular size which is characteristic of such esterification reaction.

\subsection{FTIR and ${ }^{1} H$ NMR Spectroscopic Analysis of Phenol Based Novolac Resin}

It is evident from Fig. 1 that there is a band in the region of $3000-3620 \mathrm{~cm}^{-1}$, which is due to phenolic methylol hydroxyl $(-\mathrm{OH})$ vibration present in the novolac resin. A band in the region of $1315-1409 \mathrm{~cm}^{-1}$ is due to the presence of hydroxyl groups (methylol hydroxyls) in the molecules. The band located at $1500 \mathrm{~cm}^{-1}$ is assigned to phenolic ring substituted at the ortho-, para positions. The same could be further confirmed by the appearance of absorption band at $820 \mathrm{~cm}^{-1}$ which clearly indicates the presence of aromatic ethylene bonds $(\mathrm{C}=\mathrm{C})$ of phenolic ring. A peak near $1200 \mathrm{~cm}^{-1}$ also appearing in the spectrum is due to stretching vibration of phenol-O group. The peak appearance in the IR spectra confirms the formation of novolacs with ortho- and para-substituted phenolic rings connected via methylene linkages.

In the ${ }^{1} \mathrm{H}$ NMR (Fig. 2) a multiplet observed in the range of 3.4-4.2 ppm might be due to aliphatic protons present in the structure of the novolac resin. The appearance of multiplet near 6.4-7.4 ppm might be due to the aromatic protons present in the structure. There also appears another multiplet in the region of 9.0-9.6 ppm, which is assigned to the hydroxyl group functionality of the novolac resins. The integrated area of the multiplites is taken as a measure of aliphatic, aromatic and hydroxyl proton units in the structure. 


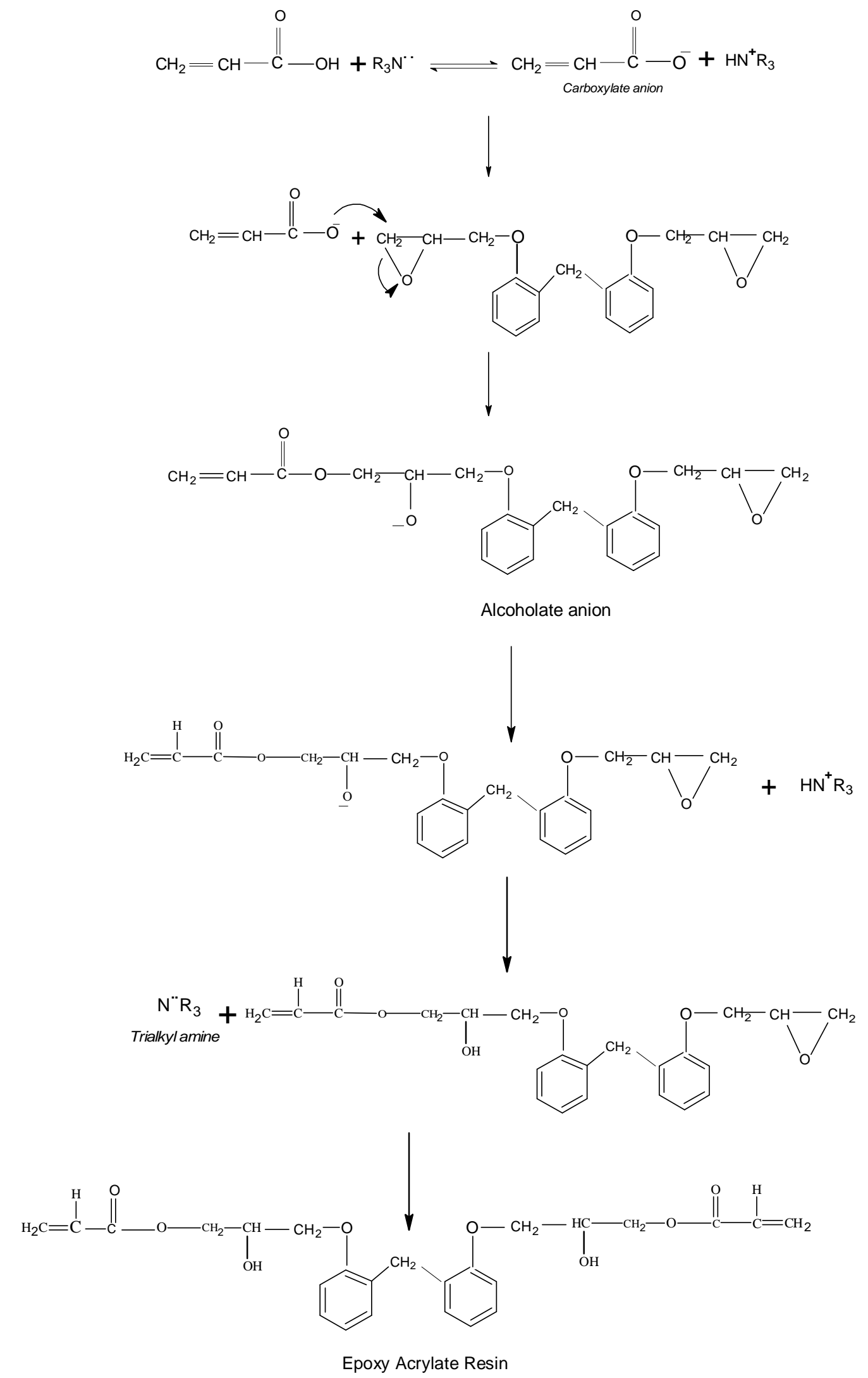

Scheme 4 


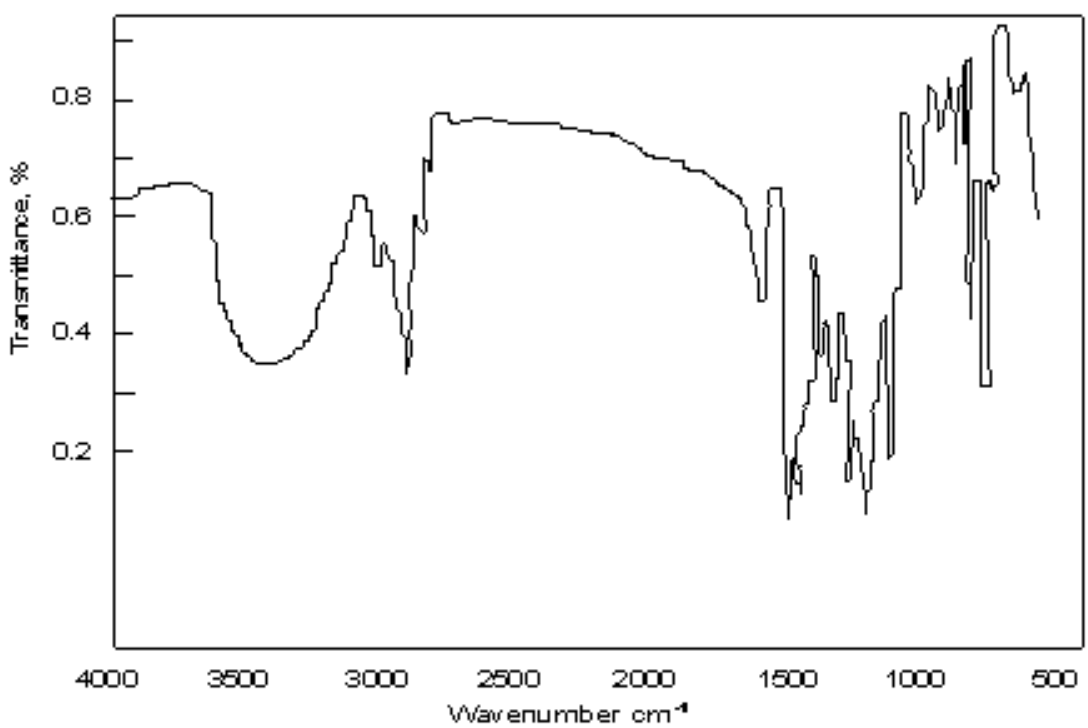

Fig. 1. FTIR spectrum of novolac resin

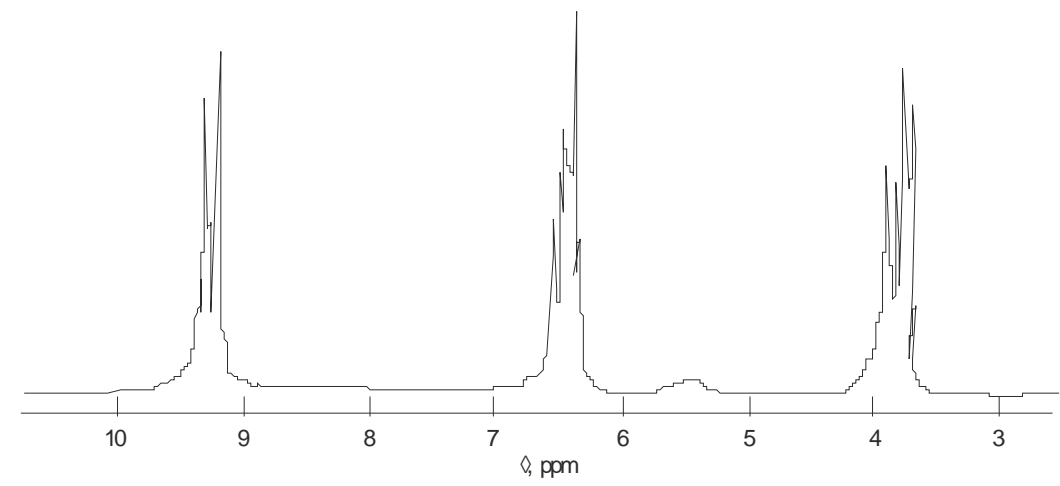

Fig. 2. ${ }^{1} \mathrm{H}$ NMR spectrum of novolac resin

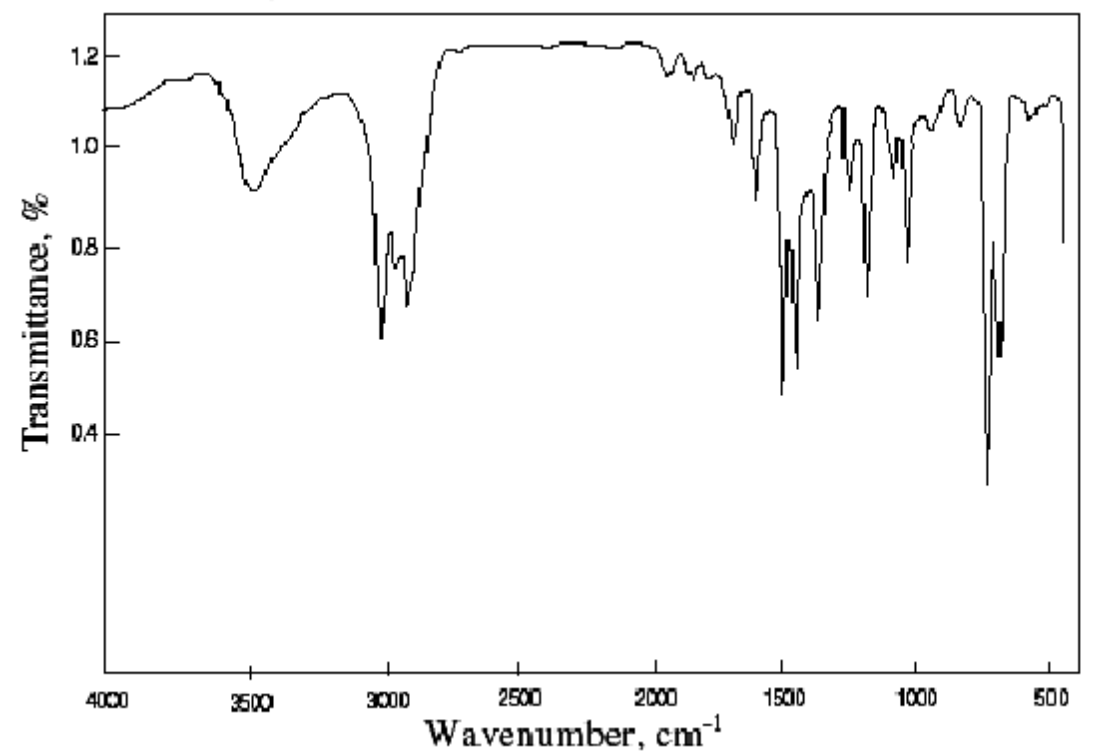

Fig. 3. FTIR spectrum of novolac epoxy resin 


\subsection{FTIR and ${ }^{1} \mathrm{H}$ NMR Spectroscopic Analysis of N ovolac Epoxy Resin}

It is evident from Fig. 3 that there is a broad band near 3200-3650 $\mathrm{cm}^{-1}$, which can be attributed to the hydroxyl stretching vibration of phenolic group. The absorption band near $2890 \mathrm{~cm}^{-1}$ might be due to $\mathrm{CH}_{2}$ vibrations. The absorption bands near 1520, 1590 and $1620 \mathrm{~cm}^{-1}$, might be due to vibration of substituted aromatics. The absorption band at 1255-1268 $\mathrm{cm}^{-1}$ indicates the presence of oxirane group of epoxy. The absorption bands near 920 and $880 \mathrm{~cm}^{-1}$ appear due to the ring deformation of terminal epoxy group in each spectrum, which confirms the presence of epoxy groups in this polymer. The regions of 750-790, 820-850 and
$910-920 \mathrm{~cm}^{-1}$ might be due to $o-, p$ - and ring-substitution of phenolic ring respectively.

In the ${ }^{1} \mathrm{H}$ NMR spectra (Fig. 4) there is a multiplet in the region of $2.38-2.90 \mathrm{ppm}$, which might be due to presence of aliphatic protons attached to the $>\mathrm{CH}_{2}$ group of the epoxy ring. A broad singlet appeared in Fig. 4 near 3.08-3.33 ppm, which might correspond to the aliphatic protons attached to $>\mathrm{CH}$ group of the epoxy ring. Appearance of multiplet in the region between 3.39 and $3.43 \mathrm{ppm}$ corresponds to the overlapping of the aliphatic protons due to $>\mathrm{CH}_{2}$ group attached to epoxy ring on one side and oxygen $(\mathrm{O})$ to the other side, and due to $>\mathrm{CH}_{2}$ attached to the aromatic ring on both the sides. A multiplet in the region between 6.64 and $7.45 \mathrm{ppm}$ might be due to the aromatic protons of benzene nucleus .

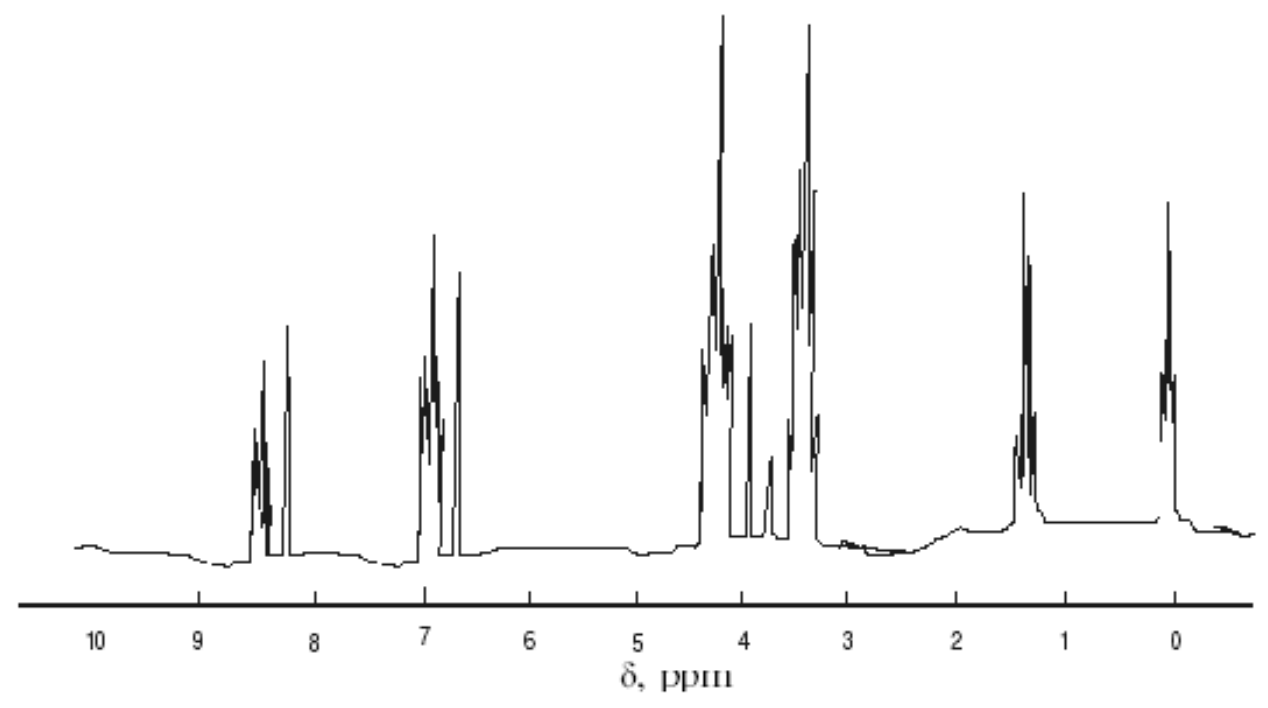

Fig. 4. ${ }^{1} \mathrm{H}$ NMR spectrum of novolac epoxy resin

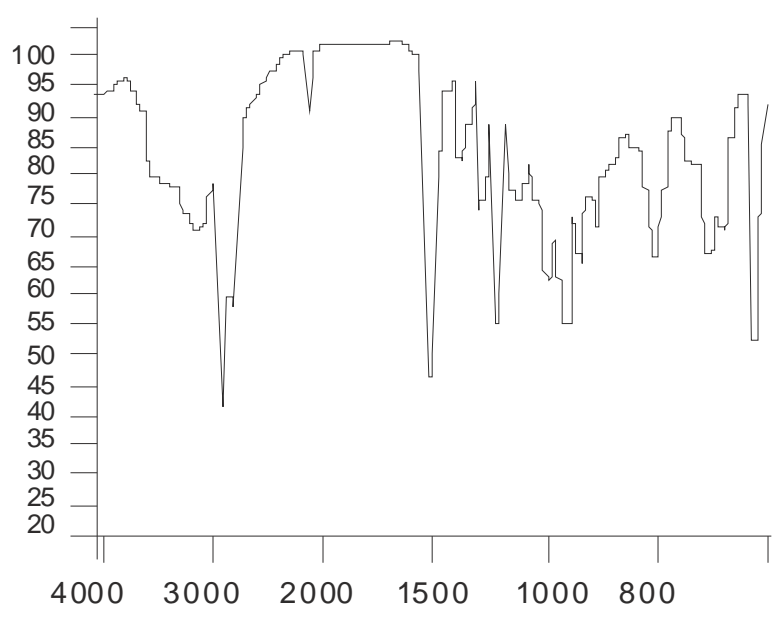

Fig. 5. FTIR spectrum of novolac acrylate resin 


\subsection{FTIR Spectroscopic Analysis of N ovolac Acrylate Resin}

The IR-graph of novolac acrylate shown in Fig. 5 exhibits band in the region of $1775 \mathrm{~cm}^{-1}$ and $1750 \mathrm{~cm}^{-1}$, which confirms the presence of ester linkages. The epoxy bands are not so prominent in these graphs due to the opening of oxirane ring during the process of acrylation. A band corresponding to acrylol double bond appeared at $1610 \mathrm{~cm}^{-1}$ and $1615 \mathrm{~cm}^{-1}$ for acrylate resin and a broad band near $3454 \mathrm{~cm}^{-1}$ shows the presence of $-\mathrm{OH}$ group.

\subsection{FTIR Spectroscopic Analysis of Silicone Acrylate}

IR spectra of silicone acrylate resin shows the bend at $1040-1070 \mathrm{~cm}^{-1}$, which is due to the presence of $\mathrm{Si}-\mathrm{O}-\mathrm{Si}$ linkage. The band at $1261 \mathrm{~cm}^{-1}$ confirms the presence of Si-Me linkage.

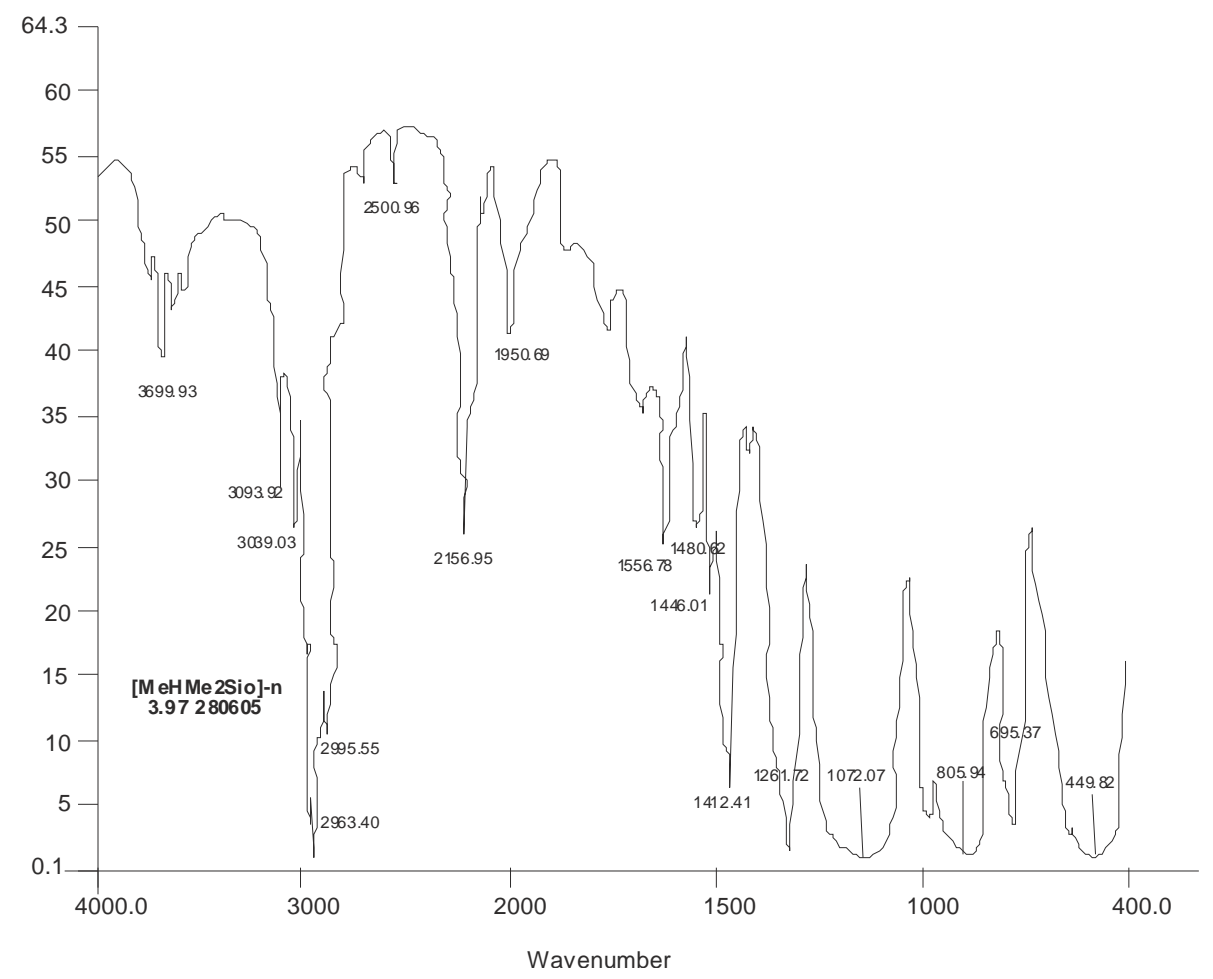

Fig. 6. FTIR spectrum of silicone acrylate resin

Mechanical properties of UV cured siliconized epoxy resin

\begin{tabular}{|c|c|c|c|c|}
\hline Sample No. & Scratch hardness, g & Pencil hardness & Flexibility, 1/4" Mandrel & Gloss, \% \\
\hline I & 1.700 & $4 \mathrm{~h}$ & Pass & $92-95$ \\
\hline II & 1.750 & $4 \mathrm{~h}$ & Pass & $92-97$ \\
\hline III & 1.800 & $5 \mathrm{~h}$ & Pass & 100 \\
\hline IV & 1.700 & $4 \mathrm{~h}$ & Pass & $92-95$ \\
\hline V & 1.750 & $4 \mathrm{~h}$ & Pass & $92-97$ \\
\hline VI & 1.800 & $5 \mathrm{~h}$ & Pass & 100 \\
\hline
\end{tabular}

\subsection{Mechanical Properties of Cured Films}

The coated tin, mild steel and glass panels were subjected to the following performance test by BIS-101 specifications shown in Table 4.

\subsubsection{Flexibility}

The flexibility of the coated films was determined with the help of $1 / 4$ " mandrel. The coated tin panels were bent to $180^{\circ}$ by using a mandrel (Sheen Instrument Limited, 
England). All the samples passed flexibility test, samples III and VI exhibit the highest flexibility because they contain higher percentage of silicon compounds as compared to others.

\subsubsection{Scratch hardness}

Hardness is the resistance of a material to indentation of scratching. The most widely used hardness test for coatings are scratch hardness. Load bearing capacity of the films was measured by using scratch hardness tester (ASTM D 5178, Sheen Instrument Limited, England). The panels were loaded with different weights until a clear scratch showing the bare metal surface was seen; scratch hardness of samples III and VI with higher percentage of silicon compound was higher.

\subsubsection{Gloss}

After watching the sample from different angles it has been observed that all the samples possess excellent gloss.

\subsubsection{Pencil hardness}

In this test sample strip is drawn under a pencil (for example one with changeable $0.5 \mathrm{~mm}$ flattened leads) until reaching a hardness grade which will scratch the surface. The hardness value of coating is then assigned as $\mathrm{H}, 2 \mathrm{H}, 3 \mathrm{H}$, etc., which therefore signifies the hardness grade. Different pencils of different grades have been used and it has been found that samples III and VI show maximum extent of hardness due to higher percentage of silicone.

\subsection{Chemical Resistance Properties of Cured Films}

To evaluate the overall performance of the coatings, the coated films were exposed to various acids, alkalis and water. The coated panels were sealed from three sides by using molten paraffin wax before dipping in various chemicals.

\subsubsection{Resistance to acids}

Sulfuric acid, hydrochloric acid and acetic acid were dissolved in water to make solution of $5 \%$ and $10 \%$ concentration on a weight per volume basis. The coated panels were then dipped in these acid solutions for $108 \mathrm{~h}$ to check their resistance against various acids. Samples which possess high percentage of silicone compound show better resistance (Table 5).

Resistance of UV cured siliconized epoxy resin towards acids

Table 5

\begin{tabular}{|c|c|c|c|c|c|c|}
\hline \multirow{2}{*}{ Sample No. } & \multicolumn{2}{|c|}{ Acetic acid } & \multicolumn{2}{c|}{ Sulfuric acid } & \multicolumn{2}{c|}{ Hydrochloric acid } \\
\cline { 2 - 7 } & $5 \%$ & $10 \%$ & $5 \%$ & $10 \%$ & $5 \%$ & $10 \%$ \\
\hline I & 5 & 4 & 4 & 3 & 5 & 5 \\
\hline II & 5 & 5 & 5 & 4 & 5 & 4 \\
\hline III & 5 & 5 & 5 & 5 & 5 & 5 \\
\hline IV & 5 & 5 & 5 & 4 & 5 & 4 \\
\hline V & 5 & 5 & 4 & 5 & 4 & 4 \\
\hline VI & 5 & 5 & 5 & 5 & 5 & 5 \\
\hline
\end{tabular}

Note: 5 means film unaffected; 4 - loss in gloss; 3 - blistering in films

Table 6

Resistance of UV cured siliconized epoxy resin towards distilled and saline water

\begin{tabular}{|c|c|c|}
\hline Sample No. & Distilled water & Saline water \\
\hline I & 5 & 5 \\
\hline II & 5 & 5 \\
\hline III & 5 & 5 \\
\hline IV & 5 & 5 \\
\hline V & 5 & 5 \\
\hline VI & 5 & 5 \\
\hline
\end{tabular}

Note: 5 means film unaffected 
Resistance of UV cured siliconized epoxy resin towards alkali

\begin{tabular}{|c|c|c|c|c|}
\hline \multirow{2}{*}{ Sample No. } & \multicolumn{2}{|c|}{ Sodium hydroxide } & \multicolumn{2}{c|}{ Ammonium hydroxide } \\
\cline { 2 - 5 } & $5 \%$ & $10 \%$ & $5 \%$ & $10 \%$ \\
\hline I & 5 & 4 & 5 & 5 \\
\hline II & 5 & 5 & 5 & 5 \\
\hline III & 5 & 5 & 5 & 5 \\
\hline IV & 5 & 5 & 5 & 5 \\
\hline V & 5 & 4 & 5 & 5 \\
\hline VI & 5 & 5 & 5 & 5 \\
\hline
\end{tabular}

Note: 5 means film unaffected; 4 - loss in gloss; 3 -blistering in films

\subsubsection{Resistance to distilled water and saline water}

Coated cured panels were dipped in distill water and saline water at ambient temperature for $108 \mathrm{~h}$. The panels were observed for a visible change in the same condition. All the samples exhibit excellent resistance as shown in Table 6.

\subsubsection{Resistance to alkali}

To check the alkali resistance of the samples coated glass panels were placed in $5 \%$ and $10 \%$ solution of $\mathrm{NaOH}$ and $\mathrm{NH}_{4} \mathrm{OH}$ for $108 \mathrm{~h}$ on a weight per volume basis. All the samples exhibit good resistance towards the alkali except few showing loss in gloss in $\mathrm{NaOH}$ solution as shown in Table 7.

\subsection{TGA Analysis}

Activation energy $(E)$ for the thermal decomposition of the UV-cured epoxy has been evaluated from the dynamic thermograms. Fractional decomposition $(\alpha)$ for respective temperature has been calculated from TGA graph shown in Fig. 7. Higher value of activation energy in the system may be due to the presence of

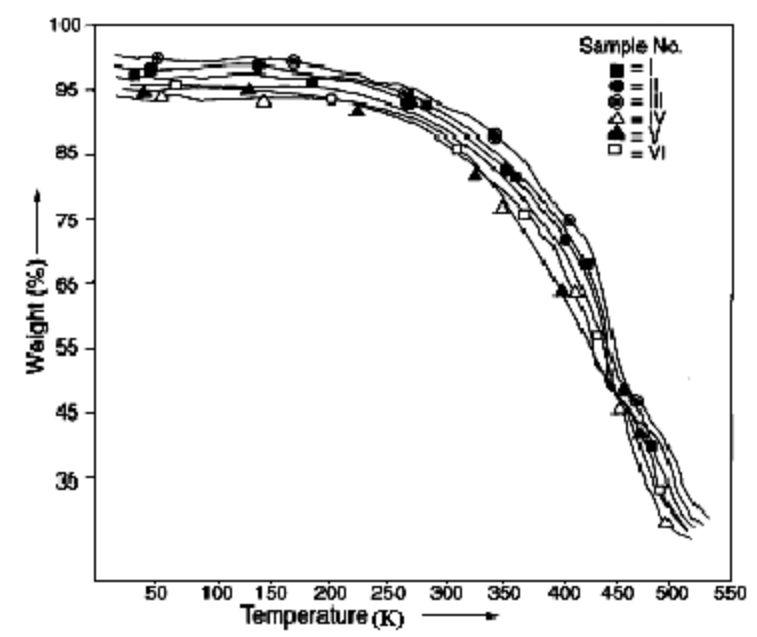

Fig. 7. Thermogravimetric graph polynuclearity in the resin (because of the presence of silicon in the resin). High activation energy for the decomposition of the systemleads to better thermal stability of the compounds [20,21].

\section{Conclusions}

The thermal stability of the epoxy resin increases to about $693 \mathrm{~K}$ with the higher content of silicone. The increased activation energy with respect to increase in silicon compound up to a certain level indicates a more thermally stable cresol novolac epoxy resin system. This type of UV cured coatings may be recommended for their applications in moderately stringent environment and under moderately high temperature applications where thermal stability is the main concern.

\section{References}

[1] Helfand D.: J. Coat. Tech., 1996, 68, 73.

[2] Wegmann A.: J. Coat. Tech., 1993, 65, 27.

[3] Ahmad S., Gupta A., Sharmin E. et al.: Prog. in Org. Coat., 2005, 54, 248.

[4] Kumar S., Denchev Z. and Alagar M.: Eur. Polym. J., 2006, 42, 2419.

[5] Kumar S. and Sankaranarayan T.: Prog. in Org. Coat., 2002, 45, 323.

[6] Preston J.: Heat Resistance of Polymers [in:] Encyclopedia of Chemical Technology, 2n edn., John Wiley \& Co. New York 1967.

[7] Susumu F., Masaharu W. and Takkaki M.: Chemical Abstracts, 1987, 106, 85682d.

[8] Kimyasu S., Atsufumi S. and Masayuki E.: Chemical Abstracts, 1995, 122, 108844e.

[9] Li L., Xu W., Wu. Y. et al.: Prog. in Org. Coat., 2007, 53, 77. [10] Kayanam-Apohan N., Amanoel A., Arsu N. and Gungor A.: Prog. in Org. Coat., 2004, 49, 23.

[11] Samuelsson J., Sundell P. and Johnson M.: Prog. in Org. Coat., 2004, 50, 193.

[12] Bongiovanni R., Sangermano M., Malucelli G. and Priola A.: Prog. in Org. Coat., 2005, 53, 46. 
[13] Kim H., Ju H. and Hong J.: Eur. Polym. J., 2003, 39, 2235.

[14] Zhang J., Windall G. and Boyd I.: Appl. Surf. Sci., 2002, 186, 568 .

[15] Hasegawa K., Matsumuto A. and Otsuko K.: Osaka Mini Tech. Res. Inst., 1996, 70,115.

[16] Korshak V. and Vinogrodova S.: [in:] Burdon J. (Ed.) Polyesters. Pergamon Press, Oxford 1995.

[17] Hood J., Blount W. and Sade W.: J. Coat. Techn., 1986, $\mathbf{5 8}, 49$.

[18] Urabanski J., Czerwinkski W., Janika K. et al.: Handbook of Analysis of Synthetic Polymers and Plastics. Ellis Horward ltd., Chicketa 1977.

[19] Lee H. and Neville K.: Handbook of Epoxy Resins. McGraw-Hill, New York 1982.

[20] Srivastava D. and Mathur G.: J. Macromol. Sci., 1997, 34, 59.

[21] Yee A. and Pearson R.: J. Mater. Sci., 1986, 21, 2475.

\section{УФ-ЗАТВЕРДЖЕНІ ТЕРМОСТІЙКІ ЕПОКСИ-АКРИЛАТНІ ПОКРИТТЯ}

Анотація. В роботі вивчено отримання термостабільних УФ-затверджених покриттів, виходячи з силіконакрилатів та епоси-акрилатних смол, в присутності різних за природою розчинників і фотоініціаторів. Встановлено, щзо такі покриття характеризуються високою термостабільністю (693 K) та проявляють фізичну i хімічну стійкість. Запропонований метод дає можливість отримувати термостійкі покриття, виходячи як із органічного, так $i$ неорганічного полімеру, в тому числі функцій них аміносиланів, беручи за основу епоксидний акрилат.

Ключові слова: термостійкість, силіконоакрилат, УФзатвердження. 